\title{
From Cloud to BIM Model of the Built Environment: The Digitized Process for Competitive Tender, Project, Construction and Management
}

\author{
Franco Guzzetti, Karen Lara Ngozi Anyabolu, Lara D’Ambrosio \\ and Giulia Marchetti Guerrini
}

\begin{abstract}
The new methodologies of surveying and modelling allow for important advantages in the whole life cycle of a building. Specifically, the point cloud, with its richness in detail, can be the basis to set an interesting and useful work of creating a BIM model. Inside, all the objects with a well-structured informative part allow for the interoperability between the different figures involved in the process. One of the main aims can be the use of a BIM model to manage the competitive tender in the public works in order to control time and costs. The case study is about urban open space: analysis of digital and integrated management of a built environment.
\end{abstract}

Keywords Built environment · BIM - Urban open space $\cdot$ Competitive tender • Facility management

\section{Digitization Process of Building Construction}

The digitization of construction projects is now standard within the process that leads from concept to construction and then management over time.

In the past years, the use of BIM software has allowed users to simplify project development in its entirety, especially for new buildings. This great change in building construction is characterized by the opportunity to manage the whole process with a single tool in a clear and transparent manner. The data can be modified in real-time by anyone who is licensed, appointing party and appointed party.

As is known, most of BIM software such as CAutodesk Revit, is designed for projecting new constructions; plans, sections and components are studied in order to have an accurate drawing and standard elements. In a way, BIM can also be used for existing buildings; specifically, many issues regarding historical buildings arise but there are signs of progress in modelling irregular elements.

F. Guzzetti ( $₫)$ · K. L. N. Anyabolu · L. D'Ambrosio · G. Marchetti Guerrini Architecture, Built Environment and Construction Engineering-ABC Department, Politecnico di Milano, Milan, Italy

e-mail: franco.guzzetti@polimi.it 
This paper illustrates another part of the construction that is not currently considered for digitization: the open urban space.

Modelling the open space, as a square, a garden or simply a portion of a street, is actually an interesting challenge because the bases are still to be invented and several experiences remain to be analysed.

While for buildings there is a form of legislation issued by the International Organization for Standardization and national governments, regarding open spaces the current information derives, in our experience, from a topographic database. Working on the open space there is a new purpose to increase the database and improve the management of built constructs in general.

The study attempts to analyse in detail the creation of a part of a square and crossroad, in order to understand limits and the potential of BIM modelling, considering a hypothetical competitive tender or maintenance intervention in an urban open space. The process and an idea of object organization is described in this paper.

\section{Reference Regulations}

At the beginning of the year, in Italy, parts 1 and 2 of UNI EN ISO 19650 have been received and published. The legislation deals with new dynamics related to the digitization and introduction of BIM in the building construction process.

According to European legislation, UNI EN ISO 19650-1 and 19650-2 "Organization and digitization of information about buildings and civil engineering works, including building information modelling (BIM)" describe the principles and the data flow during projects. The figures involved in the process exchange data and information by using the same digital environment in which documents can be shared, verified and updated.

The UNI defines a model of work organization in teams and between the different parties, while also setting guidelines for the information flow.

In the document, classifications and standardization refer only to building projects. As in the software (for instance, (CAutodesk Revit), all the components and the organization of the elements are thought of in the same way as the construction process. This concerns structures, columns and beams, walls with relative stratification, finishes. All things considered, nowadays, it is actually a significant step forward in the management and advancement of using BIM but considering the open spaces, there still are several gaps, especially related to terminology and categorization of the elements. 
The use of standards approved by all the organizations involved is important to reach the main aim of planning in BIM: the interoperability can be fast and clear, the errors can be avoided during the project and construction phases, the correctness of data is certain, and huge savings can be made by checking all the phases in advance (Ciribini et al. 2016).

Furthermore, it is interesting to have a single tool in order to obtain a wide range of cases to identify in an easier way causes of issues and solutions.

\section{Level of Development: Geometry and Information}

The legislation defines, in all respects, the internal organization of a project team, the relationship among the figures, particularly appointed and appointing parties, the review and delivery process (Caffi et al. 2014). Furthermore, the description of roles is presented including that of the Task Information Manager who covers an essential position relating to following standards throughout the entire process; they direct the production of information based on the agreed procedures. In fact, by legislation, there are certain standards, however, the level of development is defined in the initial client request; the detail is chosen based on the needs.

The LOD, level of development, is a significant topic that allows to uniform BIM modelling on an international level.

Thanks to this classification, it is possible to immediately recognize the level of detail, both geometrical and informative. To a LOD 100 the geometry is simple, and the correlated data is less (indispensable for the definition of geometry); instead, a LOD 400 object has a more detailed geometry and a greater amount of data, up to the producer's name of the item.

The LOI or level of information (as defined in UNI 11337) is often a priority over geometry. The possibility of managing the entire life cycle of a building is due to the presence of data and metadata that allows users to extrapolate statistics and evaluations. With a BIM model, it is possible to obtain information about costs and time, which are the most critical parameters related to a competitive tender or maintenance intervention, as well as the quality of the projects.

Based on the LOD reached, the model can be questioned in relation to different specifications and topics, and all the data can be considered within a time frame equal to the life of the building: the added value of a BIM model is time.

As an example, a competitive tender which concerns the project of a new school in Melzo is reported. The participating companies could update their documentation through a predefined platform and, in real time, the public administration would be able to check quotations and schedules and compare different offers.

One of the interesting points concerns the difference between the initial cost (essentially the same for all companies) and the cost of the building at 50 years, which creates a curious gap among the participants (Fig. 1). This gap refers basically to maintenance; therefore the importance of counting the management costs in the overall costs of work is highlighted. 


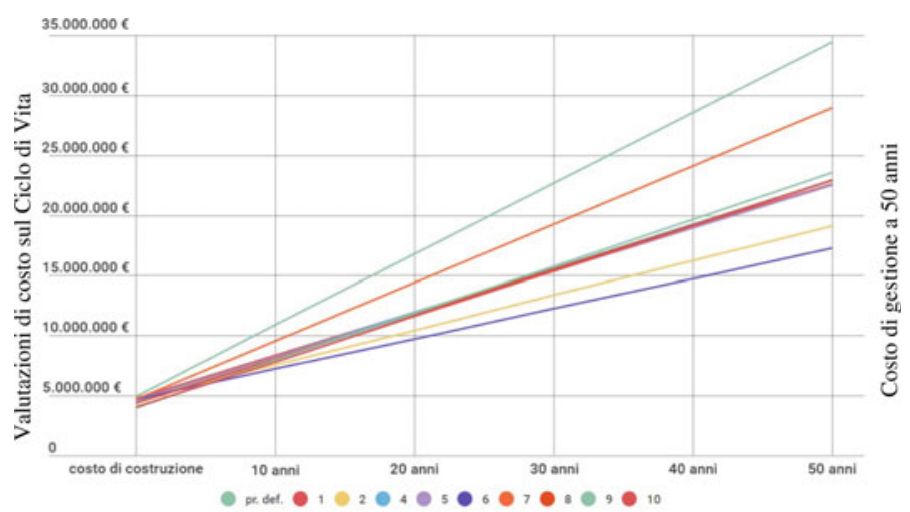

Fig. 1 Life cycle cost of a new school in Melzo: offer of different participating companies at the competitive tender (Di Giuda G.M., Villa V., Paleari F., Schievano M.)

With a tool like a BIM model, a fundamental aspect is that the data is not only predictable but also correct and consequent to the design choices made.

\section{Case Study: From Point Cloud to BIM Model of a Square in Milan}

Back to the analysis of open space, our experience concerns surveying and modelling; in particular, the creation of a BIM model of the external environment (Fig. 2) including all the relative elements visible and invisible (underground utilities) (Guzzetti et al. 2018).

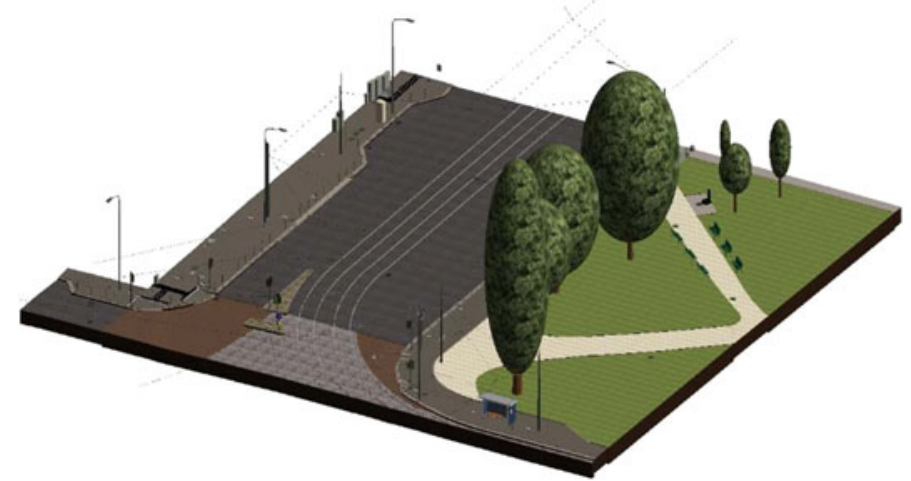

Fig. 2 View of the final BIM model with all the elements designed 
The question is: what does the process of digitization involve in open urban areas?

How is it possible to manage a project of an external space using BIM in order to have advantages for a competitive tender, maintenance and renewal project? Which is the difference in using GIS?

The first phase of the work has been addressed through a laser scanner survey.

This part was particularly challenging since the urban area is vast and full of objects that make on-site scans difficult; both for objects that are necessary to survey and for objects that contribute noise to the cloud (such as vehicles or people).

The positioning of the targets was difficult next to the street because of its width, approximately $20 \mathrm{~m}$; this is more than the minimum distance that must be between the instruments and their targets. Despite this problem, it is necessary to focus on the targets in order to join the scans in the elaboration phase.

After the elaboration of the 26 scans, a point cloud is obtained, which is usable as a foundation for the modelling phase. The transition from point cloud to the 3D model is a delicate stage in which the level of correspondence is defined between the two elements.

It is noticeable that the level of accuracy of this type of survey is elevated (Barazzetti et al. 2015). The instrument used, a Faro Focus 3D HDR CAM2 laser scanner, has a high precision and the point cloud ensures a $2 \mathrm{~mm}$ degree of accuracy. This value is very small whereas the main aim is to create a BIM model of an open urban space referred to as the hypothesized topic; there is no interest in obtaining a high-precision modelling of a sidewalk or a streetlight, so the detail is redundant compared to the needs.

This concept is entirely different compared to the level of detail.

The precision of adherence among the points of the cloud and the solid in BIM is defined at the beginning, based on the specific needs of the project.

The LOD, instead, is not connected to the point cloud but is referred only to the model. It could take, for instance, the creation of a portion of the sidewalk.

The real surface, which is derived from the point cloud is studded with noise (presence of people, moving vehicles and other disturbing elements); the modelling part is made by following 3D polylines created as guidelines on (CAutodesk AutoCAD. These paths are positioned in the middle of hundreds of points considering an adequate scale.

This type of precision does not interfere in any way with the possibility of creating a LOD 100 element rather than 400 .

The definition of detail lies in the amount of data entered and, in addition, through the enrichment of geometry it is possible to improve the quantity of information.

The sidewalk can be modelled in different ways:

- geometry is extremely simplified and is created with a unique linear slope

- geometry is more complex with different slopes in order to follow the cloud more faithfully considering all the discrepancies

- the geometry is simplified but the stone ashlars are defined as single and countable elements with the same section. 
From the methods listed here, it is clear that modelling can take place in different ways.

The goal is to find the right balance between the precision of representation and the elements that must be represented (Guzzetti et al. 2019).

The amount of data depends on the model's final purpose: in this case, the intent is to generate a BIM for a competitive tender or a maintenance program (shared among different figures).

The simplification of geometries is desirable, maintaining the fundamental data of elements and surfaces in order to have a more performing and specific model (Fig. 3).

The inclusion of the data necessary to be able to interact with the model and draw conclusions regarding the quantity and costs of the materials is essential.

Another example is referred to as the family of a traffic light, created specifically by our team.

The advantage of having a BIM model is that in case of maintenance the number of elements could be known immediately, the total economic amount and the condition of the product as well (only as an inserted parameter); thanks to this, it is possible to avoid failure by replacing the element over time (Osello et al. 2018).

In certain circumstances, it could be conceived that working in a GIS environment there could be the same results: points, lines, surfaces can contain the same data as a BIM model.

The differences essentially concern three topics as listed below.

- GIS is undoubtedly an adequate tool to manage data on a territorial scale. However, the cartographic base, DBT, presents a tolerance of about $40 \mathrm{~cm}$ due to a 1:1000 drawing scale. For instance, the correct position of manholes and underground networks is important, and BIM precision is the best solution.

- The better precision of the BIM model allows for more accurate quantification of square meters of materials. In the same way, the number of certain elements can be known, which are not represented in GIS: for example, the single stones of a sidewalk curb.

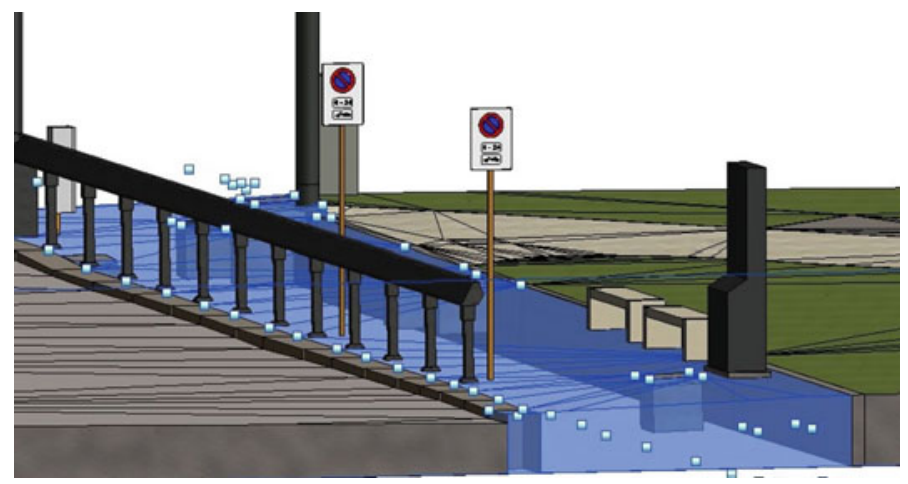

Fig. 3 Flooring parts: curb as single elements and sidewalk with a linear slope 
- The visualization in a BIM model allows users to view three-dimensional objects with their materials and it is extremely useful to verify the landscape impact of a renewal, or of an installation of different urban furniture or of the organization of temporary events.

\section{Categorization of BIM Elements}

Following these considerations, hoping for the use of BIM in the future, the next step for the representation of external spaces is the need to create an adequate official system for cataloging objects as is the case today for topographic databases with .shp files. At the regional level, technical specifications are issued to regulate the representation of cartography in GIS.

In these specifications, in addition to the general information relating to cartographic operations, there are subdivisions to categorize the various elements represented. The data is ordered according to layers, themes and classes; the defined scheme allows users to collect all the elements present in the territory.

In a BIM environment, there is a lack in the organization of elements of open urban space (Malinverni et al. 2019). Therefore, the primary aim will be creating an informative model in order to manage the external spaces with a criterion that can be repeatable and standard.

Analysing the research carried out, the attempt is to generalize and define a logical scheme following the categories present in DBT: all the existing elements are considered.

The first macro layer defines the typology of terrain, which should cover $100 \%$ of the surface in the model: pedestrian and vehicular circulation areas, green areas, cycle lanes and objects are included in the categories.

The underground utilities are another category that includes networks, terminals and connections relating to installations on public terrain (Fig. 4).

These elements are further divided according to their position under the ground and above the ground. The emerging parts and the underground networks are defined using MEP modelling with (C)Autodesk Revit MEP.

The vegetation is another section that partly refers to the terrain described before (green areas) and contains within it everything that can be called urban green; in addition to the different types of areas, the planting and sports fields are listed. In the subsoil, the plant roots of an area could be inserted in order to verify possible interferences with underground utilities (Cattaneo 2010).

This could be the basis for the management of open urban spaces in a BIM environment (Fig. 5). Obviously, the categories and the subdivisions have to be implemented, with subsequent studies, considering every type of material and product. 
Fig. 4 The family of a manhole, the part under the ground it is connected to piping on MEP (@)Autodesk Revit)

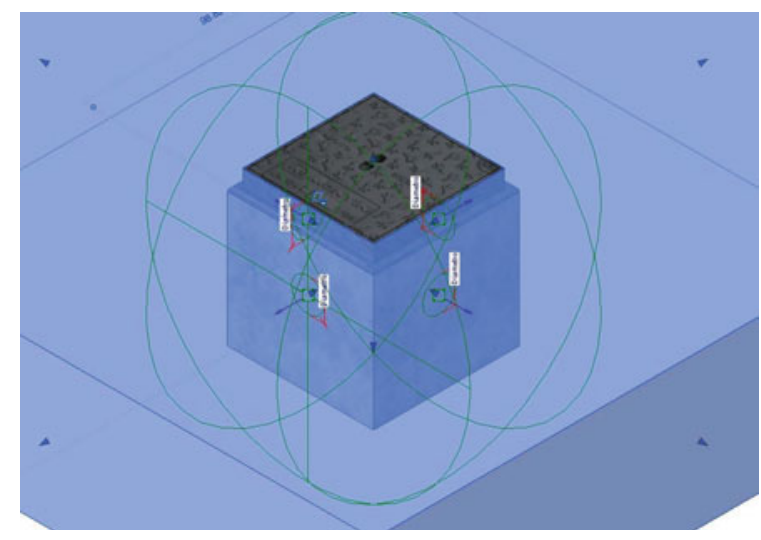

\section{Conclusion}

Facility management is everything that concerns maintenance and organization within a company. It is every service that facilitates business activities; it discusses safety, personnel, telecommunications.

The sector also concerns buildings, structures, facilities and maintenance.

The "management of structures" (physical or virtual) is a fundamental issue for the proper functioning of a company. It is clear how the BIM, in this case, allows for optimal management of all the information concerning every single element of the building.

For example, if all the lighting points of electrical systems with related lighting objects are inserted in a BIM model, it is possible to obtain a variety of information. The number of street lamps, but also the total electricity consumption; even more interesting can be the analysis of the elements over time, and therefore it is possible to understand how long it will take to intervene with a replacement of the bulbs.

Regarding open spaces, it is possible to apply the same methodology, furthermore, to analyse the whole areas with a single tool, a BIM model, guaranteeing a global view that is usually difficult to have, especially in urban areas.

The interoperability is an interesting feature for the management of all the services in a city by the public administration. The maintenance over the years could be analysed immediately in order to define a priority scale and to manage the economic balance sheet.

Furthermore, it would be key to involve suppliers who could share their information in order to provide accurate data and collaborate with other users. 
From Cloud to BIM Model of the Built Environment ...

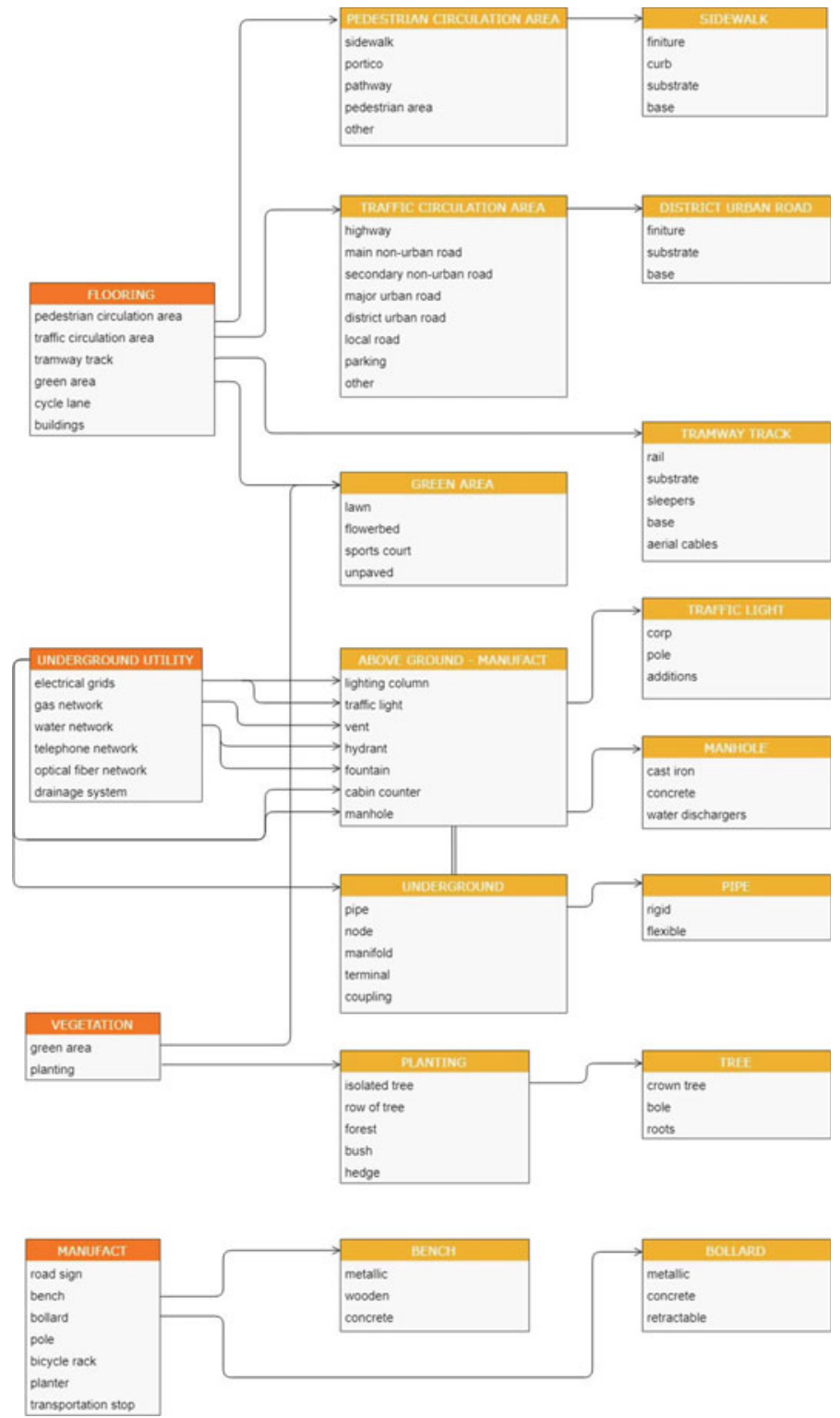

Fig. 5 The logical scheme of categorization of elements in a BIM environment 


\section{References}

Barazzetti L, Banfi F, Brumana R, Previtali M (2015) Creation of parametric BIM objects from point cloud using NURBS. Photogram Rec 30(152):339-362. https://doi.org/10.1111/phor.12122

Caffi V, Daniotti B, Lo Turco M, Madeddu D, Muscogiuri M, Novello P, Pavan A, Pignataro M (2014) Il processo edilizio supportato dal BIMM: l'approccio InnovANCE/BIMM enabled construction processes: the InnovANCE approach. In: Conference: convegno ISTeA 2014 Energia, sostenibilita' e dematerializzazione operativa. La ricerca scientifica sulla Produzione Edilizia nell'era della digitalizzazione e delle nuove sfide ambientali nel Settore delle Costruzioni At: Bari, Politecnico di Bari

Cattaneo N, Di Maria F, Privitera A, Guzzetti F, Viskanic P (2010) Terreno Comune. ACER n 6/2010. Verde Editoriale, pp 51, 53

Ciribini A, Mastrolembo Ventura S, Bolpagni M (2016) La validazione del contenuto informativo è la chiave del successo di un processo BIM-based. https://doi.org/10.14609/Ti_2_15_1i

Di Maria F, Guzzetti F, Privitera A, Viskanic P (2005) Progetto verde Milano: il censimento e la gestione del verde con strumenti Web Gis. In: $9^{\circ}$ Conferenza Nazionale ASITA, Catania

Guzzetti F, Anyabolu KLN, D'Ambrosio L, Marchetti Guerrini G, Sarrecchia S (2018) Dal rilievo al modello BIM di una piazza. In: XXII Conferenza Nazionale ASITA, 27-29 novembre 2018, Bolzano, pp 577-584

Guzzetti F, Anyabolu KLN, D'Ambrosio L, Marchetti G (2019) Built environment: modelling the urban space. Int Arch Photogram Remote Sens Spatial Inf Sci XLII-2/W11:595-600. https://doi. org/10.5194/isprs-archives-XLII-2-W11-595-2019

Malinverni ES, Chiappini S, Pierdicca R (2019) A geodatabase for multisource data management applied to cultural heritage: the case study of Villa Buonaccorsi's historical garden. Int Arch Photogramm Remote Sens Spatial Inf Sci XLII-2/W11:771-776. https://doi.org/10.5194/isprsarchives-XLII-2-W11-771-2019

Osello A, Ugliotti FM, De Luca D (2018) Il BIM verso il Catasto del Futuro potenziato tramite l'utilizzo della tecnologia. https://doi.org/10.26375/disegno.2.2018.15, pp 135-146

Open Access This chapter is licensed under the terms of the Creative Commons Attribution 4.0 International License (http://creativecommons.org/licenses/by/4.0/), which permits use, sharing, adaptation, distribution and reproduction in any medium or format, as long as you give appropriate credit to the original author(s) and the source, provide a link to the Creative Commons license and indicate if changes were made.

The images or other third party material in this chapter are included in the chapter's Creative Commons license, unless indicated otherwise in a credit line to the material. If material is not included in the chapter's Creative Commons license and your intended use is not permitted by statutory regulation or exceeds the permitted use, you will need to obtain permission directly from the copyright holder.

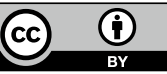

